\title{
On Leukocytes in Mammary Development and Cancer
}

\author{
Cyrus M. Ghajar \\ Life Sciences Division, Lawrence Berkeley National Laboratory, Berkeley, California 94720 \\ Correspondence: cmghajar@Ibl.gov
}

$T^{1}$ hat cancer is development gone awry is not a new concept. Most of the "hallmarks" ascribed to cancer-proliferation, invasion and induction of blood vessel growth-also occur during organogenesis and development. Therefore, tumors are not necessarily learning new tricks during their development, but how about when they metastasize? In colonizing a new organ, often with some degree of specificity, tumor cells may simply be copying a program that is executed during development by hematopoietic stem cells (HSCs) - the stem cells that ultimately generate all of the cells in our blood and maintain its homeostasis. One family of cells generated by HSCs-leukocytes-is the focus of the work by Coussens and Pollard (2012). These two scientists have woven together several studies that revolutionized the way we think of immune cells. As pointed out by the investigators (whose respective laboratories are responsible for much of the seminal work on this subject), immune cells also have a variety of trophic functions, and it is these functions that are used rationally during development, and recklessly during tumor growth.

This leads us back to metastasis. There is so much to learn about why a tumor travels from one organ to another, how it does so, and the manner by which it adapts to and ultimately flourishes (or fails) in a foreign microenvironment. And as stated above, immune cell precur- sors, HSCs, do the same. In the mouse, HSCs have originated in one tissue (the dorsal aorta), traveled to another (the placenta) via the circulation, and matured somewhere else (the liver)all before birth. Finally, HSCs make their way to the bone marrow, where they reside postnatally. Specialized niches in the bone marrow are thought to mediate HSC dormancy as a means to preserve the "stemness" of this population, and there are mechanisms in place that allow these cells to rapidly exit these environs and proliferate in response to injury. Therefore, it should not come as a surprise that a common site where micrometastases are found is the bone marrow for many cancers (including that of the breast).

Uncovering whether the same niches that control HSC expansion in the bone marrow are also responsible for maintaining quiescence of tumor cell populations is an exciting prospect, as is deciphering the precise components of these niches. Such work could explain the seemingly incongruous observation that despite an absence of clinically detectable disease, circulating tumor cells are present in the blood of post-treatment cancer patients sometimes even decades later! Perhaps the niches that regulate prolonged dormancy of tumors are dynamic and inhibit tumor proliferation while allowing them to mobilize periodically, much like for HSCs. It also stands to reason that loss of the same controls

Editors: Mina J. Bissell, Kornelia Polyak, and Jeffrey M. Rosen

Additional Perspectives on The Mammary Gland as an Experimental Model available at www.cshperspectives.org

Copyright (C) 2012 Cold Spring Harbor Laboratory Press; all rights reserved; doi: 10.1101/cshperspect.a013276

Cite this article as Cold Spring Harb Perspect Biol 2012;4:a013276 


\section{C.M. Ghajar}

that prevent HSC expansion until systemic damage occurs could awaken dormant tumors.

Shiozawa et al. (2011) have demonstrated that prostate cancer cells do in fact compete with HSCs for niches within the bone marrow, and that tumor cells are mobilized from HSC niches by similar mechanisms as for HSCs. Whether this is the case for other cancers and whether these similarities can be exploited therapeutically remain to be seen.

So what more is there to be learned about immune cells? By furthering our understanding of how solid cancers mimic and hijack components of our immune system, we may not "cure" cancer, but we very well may uncover a means to suppress some cancers into a state of permanent dormancy.

\section{REFERENCES}

* Reference is also in this collection.

* Coussens LM, Pollard JW. 2012. Leukocytes in mammary development and cancer. Leukocytes in mammary development and cancer. Cold Spring Harb Perspect Biol doi: 10.1101/cshperspect.a003285.

Shiozawa Y, Pedersen EA, Havens M, Jung Y, Mishra A, Joseph J, Kim JK, Patel LR, Ying C, Ziegler AM, et al. 2011. Human prostate cancer metastases target the hematopoietic stem cell niche to establish footholds in mouse bone marrow. J Clin Invest 121: 1298-1312. 


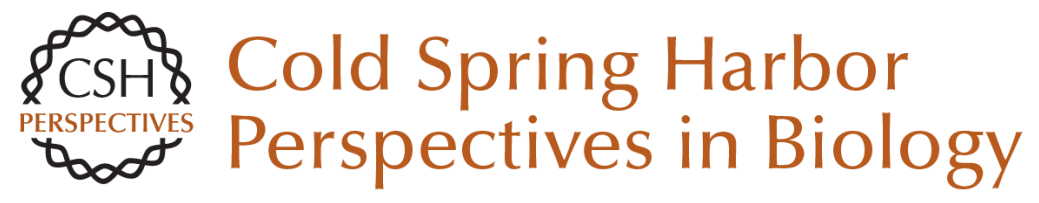

\section{On Leukocytes in Mammary Development and Cancer}

Cyrus M. Ghajar

Cold Spring Harb Perspect Biol 2012; doi: 10.1101/cshperspect.a013276

Subject Collection The Mammary Gland as an Experimental Model

On the Role of the Microenvironment in Mammary Gland Development and Cancer Derek Radisky

On Using Functional Genetics to Understand Breast Cancer Biology Kornelia Polyak

On Oncogenes and Tumor Suppressor Genes in the Mammary Gland Rushika M. Perera and Nabeel Bardeesy

On Leukocytes in Mammary Development and Cancer Cyrus M. Ghajar

On Chromatin Remodeling in Mammary Gland Differentiation and Breast Tumorigenesis Kornelia Polyak

On Hormone Action in the Mammary Gland J.M. Rosen

TGF- $\beta$ Biology in Mammary Development and Breast Cancer

Harold Moses and Mary Helen Barcellos-Hoff

A Compendium of the Mouse Mammary Tumor Biologist: From the Initial Observations in the House Mouse to the Development of Genetically Engineered Mice

Robert D. Cardiff and Nicholas Kenney
On How Mammary Gland Reprogramming

Metalloproteinases Couple Form with Function Bonnie F. Sloane

On Molecular Mechanisms Guiding Embryonic Mammary Gland Development Gertraud W. Robinson

On Stem Cells in the Human Breast Mark A. LaBarge

On Murine Mammary Epithelial Stem Cells:

Discovery, Function, and Current Status Jeffrey M. Rosen

On In Vivo Imaging in Cancer David Piwnica-Worms

Choosing a Mouse Model: Experimental Biology in Context--The Utility and Limitations of Mouse Models of Breast Cancer Alexander D. Borowsky

Mammary Gland ECM Remodeling, Stiffness, and Mechanosignaling in Normal Development and Tumor Progression Pepper Schedin and Patricia J. Keely

Molecular Mechanisms Guiding Embryonic

Mammary Gland Development Pamela Cowin and John Wysolmerski

For additional articles in this collection, see http://cshperspectives.cshlp.org/cgi/collection/

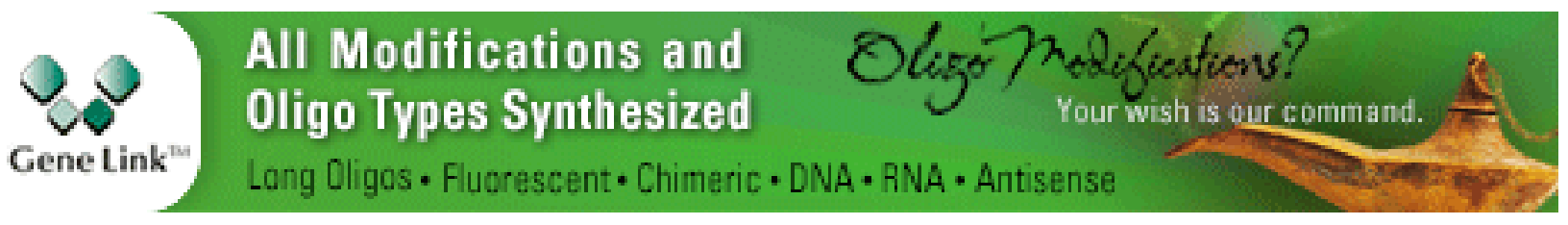


For additional articles in this collection, see http://cshperspectives.cshlp.org/cgi/collection/

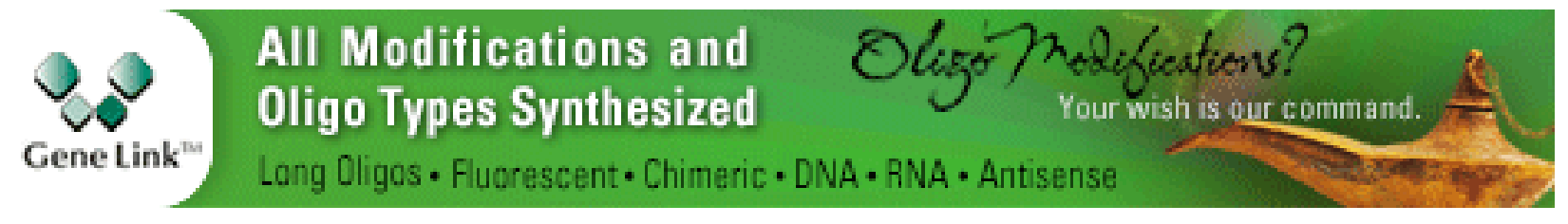

Copyright @ 2012 Cold Spring Harbor Laboratory Press; all rights reserved 